Separation and identification of antibacterial chamomile components

This is the first version (unrevised) of the paper published in Medicinal Chemistry 8 (2012) 1, 85-94.

DOI: $10.2174 / 157340612799278487$

http://www.benthamdirect.org/pages/b_viewarticle.php?articleID=3174267

\title{
Separation and identification of antibacterial chamomile components using OPLC,
} bioautography and GC-MS

\author{
Ágnes M. Móricz ${ }^{1}$, Szabolcs Szarka ${ }^{2}$, Péter G. Ott ${ }^{1}$, Éva B. Héthelyi ${ }^{2}$, Éva Szőke ${ }^{2}$, Ernő Tyihák ${ }^{1}$ \\ ${ }^{1}$ Plant Protection Institute, Hungarian Academy of Sciences, Herman O. Str. 15, 1022 Budapest, Hungary; E-mail: \\ moricz_am@nki.hu \\ ${ }^{2}$ Department of Pharmacognosy, Faculty of Pharmacy, Semmelweis University, Üllöi Str. 26, 1085 Budapest, \\ Hungary \\ Corresponding author: \\ Ágnes M. Móricz, Plant Protection Institute, Hungarian Academy of Sciences, Herman O. Str. 15, 1022 Budapest, \\ Hungary; Tel.: 0036-48-77-515; Fax.: 0036-48-77-555; E-mail: moricz_am@nki.hu
}

Keywords: antibacterial activity, bioautography, chamomile, coumarins, GC-MS, Matricaria recutita L., OPLC, spiroethers 
Separation and identification of antibacterial chamomile components

\begin{abstract}
Components of 50\% ethanolic chamomile (Matricaria recutica L.) flower extract, previously found antibacterial in a TLC-bioautographic study, were separated and isolated by the use of on-line OPLC, which consisted of an OPLC 50 BS system, an on-line coupled flow-through UV detector, and a manual fraction collector. The collected peaks were investigated by GC-MS analysis and by TLC re-chromatography with subsequent visualization, performed after use of the vanillin-sulphuric acid reagent, or under UV illumination, or applying bioautographic detection. The main compounds of the collected 11 fractions were identified by GC-MS. The results showed that the antibacterial effect of $50 \%$ ethanolic extract of chamomile is ascribable to cis-, trans-spiroethers, and the coumarins like herniarin and umbelliferone.
\end{abstract}




\section{INTRODUCTION}

There is an increased demand to discover new, effective, easy-to-obtain natural medicinal substances. Chamomile (Matricaria recutica L.) is a very familiar and widely used herb in traditional folk medicine. The flower is a common ingredient of herbal teas because it contains substances which have anti-inflammatory, sedative, analgesic, antispasmodic, antioxidant and antimicrobial properties [1-4]. The beneficial effects are related to different classes of therapeutically interesting ingredients such as essential oil components, flavonoids, and coumarin derivatives $[1,5$, and 6].

The chamomile essential oils, which are of the greatest importance among the bioactive constituents [7], consist of many active compounds such as (-)-alpha-bisabolol, chamazulene (artefact of matricine by steam distillation), (-)alpha-bisabolol oxide A and B, (-)-alpha-bisabolone oxide A, spiroethers (cis- and trans- en-yn-dicycloether), and sesquiterpenes [8].

The chamomile volatile oils showed antimicrobial activity against certain species of bacteria, fungi and viruses in vitro [9], however, Gram-positive bacteria were found more susceptible than Gram-negative ones [10]. The chamomile oils were effective e.g. against Bacillus subtilis, Staphylococcus aureus, Streptococcus mutans, and Streptococcus salivarius bacteria as well as against Candida albicans, Aspergillus niger, A. ochraceus, A. flavus, A. parasiticus, Fusarium culmorum and F. moniliforme fungi [9-12].

It has been reported that generally the aqueous chamomile extracts were more effective against moulds and yeast, while the alcoholic ones inhibited more the bacteria [13]. The inhibiting activity of hydro-alcoholic extract of chamomile was demonstrated against the growth of Staphylococcus aureus, Staphylococcus epidermidis, Streptococcus mutans, group B Streptococcus and Streptococcus salivarius, Streptococcus faecalis, Bacillus megatherium and Leptospira icterohaemorrhagiae [14]. Moreover, olive oil extract of chamomile has been proved active against Helicobacter pylori [15].

Coumarin-related compounds, ingredients in hydro-alcoholic extracts of $M$. recutita, also represent an important group of secondary metabolites of chamomile. The coumarins are phytoalexins of many species [16], exhibiting a very modest antibacterial and a stronger antifungal activity [17, 18]. Herniarin, the main coumarin component in chamomile, is a more effective antimicrobial agent than umbelliferone, which may be realized by its demethylation [19]. Umbelliferone has been described as a stress metabolite in $M$. recutita. The amount of umbelliferone characteristically, while that of herniarin mildly rose in the plant after biotic and abiotic stress influences [6, 20]. It was also observed that chamomile oil component $(Z)$-spiroether was lowered after abiotic stress, but increased in the case of biotic stress [6].

Searching for bioactive natural products requires appropriate bioassays, focused on the desired activity (e.g. antifungal, antibacterial). Layer chromatography is an ideal technical solution for the screening of drug ingredients, because of high-throughput, low cost, easy maintenance and selectivity of detection reagents [21]. Direct bioautography [22-26], linking the separation with biological detection, potentiates the fast and easy sorting of effective components in matrixes like plant extracts. In direct bioautography, the developed chromatoplates containing separated components in spots are dipped into an indicator cell suspension and, after a required incubation time, the inhibition zones are visualized using a vital dye, or suitable luminescent indicator cells [23-25]. So the evaluation of the activity is performed directly on the adsorbent layer, at the chromatographic spots.

Overpressured-layer chromatography (OPLC), as an efficient forced flow planar layer liquid chromatographic technique, results in more compact chromatographic spots and better separation efficiency than TLC-HPTLC. OPLC is also well suited for fractionation in semi-preparative ranges using analytical chromatoplates providing on-line detection and subsequent peak collection [27, 28]. This system can be applied for efficient isolation of various substance types, among others the antimicrobial components from plant extracts.

In our earlier bioautographic experiments, the components of 50\% aqueous ethanol extract showed the strongest antimicrobial effect against the plant pathogenic bacterium Pseudomonas syringae pv. maculicola, when compared with hexane, acetone and methanol extracts. The $50 \%$ ethanol extract ingredients (with the same $\mathrm{R}_{\mathrm{f}}$ values) also inhibited, although with different strength the soil bacterium Bacillus subtilis.

In this paper the OPLC separation and isolation of antibacterial components of $50 \%$ ethanolic chamomile extract, their re-chromatography, identification by means of GC-MS as well as bioautographic studies of concentrated collected peaks are demonstrated.

\section{EXPERIMENTAL}

\section{Materials}

Aluminum foil-backed normal particle silica gel $60 \mathrm{~F}_{254}$ plates (TLC, \#5554 from Merck, Darmstadt, Germany) were performed for TLC separation, as well as for OPLC but in this case the layers were sealed on all four edges. All used solvents were analytical grade purchased from Reanal (Budapest, Hungary). 
Separation and identification of antibacterial chamomile components

Triton X-100, dye reagent MTT (3-[4,5-dimethylthiazol-2-yl]-2,5-diphenyltetrazolium bromide), alpha-bisabolol, umbelliferone, and alkane standard mixture $\left(\mathrm{C}_{10}-\mathrm{C}_{40}\right.$; all even) were from Sigma-Aldrich (Budapest, Hungary).

\section{Preparation of extracts}

$150 \mathrm{mg}$ of dried chamomile (Matricaria recutita L.; collected in the end of May 2010, in Harta, in the Great Plain, Hungary) roots, leaves and flowers were macerated for $48 \mathrm{~h}$ with $1 \mathrm{~mL}$ of $50 \%$ ethanol in $2 \mathrm{~mL}$ Eppendorf tubes. Samples were vortexed for $30 \mathrm{~s}$, centrifuged $(20 \mathrm{~min}$, RCF of $10000 \mathrm{~g}$, room temperature), and $10 \mu \mathrm{l}$ of each supernatants was applied to a TLC plate that had previously been heat-treated for $3 \mathrm{~h}$ at $130^{\circ} \mathrm{C}$. For further investigation $4.5 \mathrm{~g}$ of chamomile flowers (from the market; JuvaPharma) were macerated at room temperature in 30 $\mathrm{mL} 50 \% \mathrm{EtOH}$ for $48 \mathrm{~h}$ in a screw-capped glass bottle.

\section{OPLC and TLC separations}

$50 \%$ ethanolic extracts of chamomile were fractionated by the use of Personal OPLC BS50 system (OPLC-NIT, Budapest, Hungary) in on-line operating mode $[27,28]$ on TLC layer previously heated for $3 \mathrm{~h}$ at $130{ }^{\circ} \mathrm{C}$. The conditions of the preparative on-line OPLC separation were as follows: off-line application of $0.5 \mathrm{~mL}$ extract in a 16 $\mathrm{cm}$ wide band at $3 \mathrm{~cm}$ from the edge, 50 bar external pressure, $450 \mu \mathrm{L}$ rapid mobile-phase flush, $1 \mathrm{~mL} \mathrm{~min}^{-1} \mathrm{mobile}$ phase flow rate. The mobile-phase was: 0-30 min 100\% chloroform, from 30 min chloroform-acetone 95:5 (v/v) and the detection was achieved using an on-line coupled flow-through UV detector at the wavelength of 350 and $320 \mathrm{~nm}$, respectively. The peaks collected were concentrated by cold air stream.

To control, whether, the compounds origin from the chamomile or from the adsorbent layer, the fractionation was performed under the same conditions but without sample application (blank). In this blank development 4 fractions were got. b1: 7.30-15 (in $1^{\text {st }}$ gradient step), b2: 37.30-40 (parallel with chamomile fraction 5), b3: 40-45 (similar as chamomile peak 6), and b4: 45-55 min.

The fractions were re-chromatographied on TLC layer; the No. 1-3 were developed with the mobile phase chloroform-acetone 99:1 (v/v), and the No. 4-9 with chloroform-acetone 95:5 (v/v). Developed plates were dried by a cold air stream using a hair-drier ( $5 \mathrm{~min}$ ). Visualization and detection were performed under UV illumination at 254 and $365 \mathrm{~nm}$, after use of vanillin-sulphuric acid reagent $(0.4 \mathrm{~g}$ vanillin, $100 \mathrm{~mL}$ ethanol, and $2.2 \mathrm{~mL}$ concentrated sulphuric acid) and heating $\left(110^{\circ} \mathrm{C}, 3 \mathrm{~min}\right)$ and in bioautographic system.

\section{Biological studies of OPLC fractions}

The antibacterial effect of separated chamomile components were evaluated in vitro with direct bioautography [2226] against a Gram-positive soil bacterium Bacillus subtilis (Bs) (strain F1276 [29]) and a Gram-negative luminescence-tagged transgenic plant pathogenic bacterium Pseudomonas syringae pv. maculicola (Psmlux) [30]. Bs was grown in Spizizen minimal broth [31] and Psmlux in King's B broth [32] at $28.5^{\circ} \mathrm{C}$ and at $130 \mathrm{rpm}$ on an orbital shaker to reach late exponential phase, assessed by an optical density of 1,2 (at $600 \mathrm{~nm}$ ). The dried, developed chromatoplates with separated spots were immersed for $10 \mathrm{~s}$ into these bacterial cell suspensions.

The chromatoplates dipped into Bs suspension were incubated for $2 \mathrm{~h}$ in a water-vapour chamber at $30{ }^{\circ} \mathrm{C}$, then immersed for $5 \mathrm{~s}$ in an aqueous solution of MTT (100 mg Triton X-100 and $80 \mathrm{mg}$ MTT in $100 \mathrm{~mL}$ water). The incubation of the treated chromatoplates was continued for $1 \mathrm{~h}$ until inhibition zones appeared as clear regions against a darker background where the viable, metabolically active cells could reduce the yellow MTT to the bluish MTT-formazan. The image of the bioautogram was recorded by use of a scanner (Mustek 1200 ED Plus).

For detection of the bioluminescent light emission, the chromatoplates immersed into Psmlux cell suspension were put into a transparent glass cage ensuring an air phase above the adsorbent layer, and protecting against drying. The bioautograms were documented immediately after inoculation by use of a computer-controlled cooled CCD camera (IS-4000, Alpha Innotech, San Leandro, USA) with the exposure time of $15 \mathrm{~min}$. The light emitted by the bacterial cells is closely dependent on reductive metabolic activity (which in turn depends on viability), so the darker areas on the images indicate lack of metabolic activity.

\section{Apparatus and GC-MS Conditions}

The analyses of the fractions collected were carried out with an Agilent 6890N/5973N GC-MSD (Santa Clara, CA, USA) coupled with a CTC Combi PAL (CTC Analytics AG, Zwingen, Switzerland) automatic multipurpose sampler. Separations were performed using an SLB-5ms (Sigma-Aldrich, St Louis, MO, USA) capillary column $(30 \mathrm{~m} \times 250 \mu \mathrm{m} \times 0.25 \mu \mathrm{m})$. The GC oven temperature was programmed from $60{ }^{\circ} \mathrm{C}(1 \mathrm{~min}$ isothermal $)$ to $280{ }^{\circ} \mathrm{C}$ at $10^{\circ} \mathrm{C} \mathrm{min}{ }^{-1}$ and finally held for $7 \mathrm{~min}$. Helium was the carrier gas at $1.0 \mathrm{~mL} \mathrm{~min}^{-1}$ in constant flow mode. Injection volume was $1.0 \mu \mathrm{L}$. The injector was programmed from $120^{\circ} \mathrm{C}$ to $300^{\circ} \mathrm{C}$ at $720{ }^{\circ} \mathrm{C} \mathrm{min}^{-1}$ using a 40 psi pressure pulse for $1.0 \mathrm{~min}$ while splitless time was set to $0.8 \mathrm{~min}$. 


\section{Separation and identification of antibacterial chamomile components}

The mass selective detector was equipped with a quadrupole mass analyzer and was operated in electron ionization mode at $70 \mathrm{eV}$. Full scan analyses were performed in the mass range of 40-500 amu at $3.2 \mathrm{scan} \mathrm{s}^{-1}$. Data were evaluated by MSD ChemStation D.02.00.275 software (Agilent).

The identification of the compounds was carried out by comparing retention times, retention indices and recorded spectra with data of authentic standards. Mass spectral and retention data known from the literature [8, 33-35] and the NIST 05 library were also consulted. The temperature programmed retention indices $\left(I^{T}\right)$ were calculated according to the equation given by Van den Dool and Kratz [36].

\section{RESULTS \& DISCUSSION}

$50 \%$ aqueous ethanol extracts of different chamomile organs were tested for richness in antibacterial components with the help of bioautography, a cheap and fast in vitro biological screening method. Fig. (1) shows that roots, leaves and flowers all contain compounds having growth inhibiting and/or killing effect against luminescent genetagged Pseudomonas syringae pv. maculicola (see black areas on the right picture). Although the root contains higher amount of the upper two active components (with $\mathrm{R}_{\mathrm{f}} 0.5$ and 0.65 ), the lower ones are almost totally missing. There are inhibition zones in chromatographic spots with the same $R_{f}$ values in leaf and flower extracts, but in flower extract they are stronger, therefore, flowers were selected for further investigation. We found that the yellow tubular florets contained more diverse set of antibacterial molecules than the white ligular florets (not shown).

The exploitation of OPLC in on-line operating mode seemed promising for the efficient separation and collection of ingredients of chamomile extracts (Fig. 2). The TLC re-chromatography and development with vanillin-sulfuric reagent of the fractions $1-4$, collected in the first gradient step, showed that the fractions were dominated by one or two main constituents (Fig. 3). The purity of these fractions was also proved by their photos taken under UV light (Figs. 4a, 4b). Fractions 1 and 2 contained the same two compounds in different proportion, and there was only one detectable component in fractions 3 and 4. Fractions 5-9 collected during the second gradient step looked like containing more than one or two main components (Figs. 3, 5a, 5b, 6a, and $\mathbf{6 b}$ ).

GC-MS analysis determined the following compounds in the fractions (numbered): 1- cis- and trans-spiroethers; 2cis- and trans-spiroethers with trans dominance; 3- alpha-bisabolol; 4- herniarin; 5- bisabolol oxide A and B; 6achillin; 7- matricarin; 8- matricarin; 9- small amount of palmitic, linoleic and stearic acids; 10- no determined compound, 11- umbelliferone (Table 1). They are already known compounds having been detected in chamomile [5, 33, and 37]. Figs. (7-9) demonstrate a GC-MS TIC (Total Ion Current) chromatogram of some proper chamomile fractions and the characteristic fragmentation of their main components used for identification by spectra library. After the GC-MS study of chamomile fractions, further investigations were performed to prove the presence of biologically active molecules.

The antibacterial effect of the 11 fractions was examined by bioautography against Psmlux and Bs (Figs. 4-6). Although both spiroether isomers were detected in fractions 1 and 2, it is supposed from their ratio that the first peak contained the cis, while the second the trans variant. These isomers showed stability in concentrated solutions (examined by GC-MS), but were not stable on the TLC layer, as checked by the use of 2D-TLC with the same mobile phase in both directions. The transformation could also have come off during the concentration process made by cold air stream. Despite of the fact that the trans-spiroether is more stable than the cis one, usually the cis isomer is in a higher amount than the trans in chamomile [38], and so was it in our sample, too. As to many polyacetylenes, antifungal and antibacterial activity is also attributed to chamomile spiroethers [39]. According to our results (Fig. 4), both isomers showed inhibiting/killing effect against Psmlux (Fig. 4c) as well as against Bs (Fig. 4d), however, with different strength. Comparing their activity (the correlation between their amount and the size of the inhibition zone), trans-spiroether had a bigger effect on Psmlux, than cis, while they equally inhibited Bs.

Alpha-bisabolol, found in fraction 3, is considered to be the main chamomile ingredient contributing to a mild antiinflammatory effect [40] and it is also mildly antibacterial [41]. Alpha-bisabolol did not exert any inhibition on Psmlux (Fig. 4c), even when higher amount of test compound was used (not showed). It had only a slight antibacterial effect against Bs (Fig. 4d).

Fractions 5 and 6 were collected at the front and right after the front of the stronger mobile phase used in the second gradient step, therefore they contain many substances not only from the chamomile (see Fig. 3), but also from the adsorbent bed (e.g. the binding component). Fractions 5 and 6 strongly inhibited both bacteria (Fig. 5), however, this may not be ascribed (only) to the activity of the well-known chamomile components, the bisabolol oxides or achillin, identified in these fractions by GC-MS. Achillin can be characteristically detected in Achillea species [42], but its presence in M. recutita has already been demonstrated, too [33]. The results of blank development also proved (Fig. 10) that blank fractions collected at the front and right after the front from the adsorbent layer had strong antibacterial effect against both microorganisms. 
Separation and identification of antibacterial chamomile components

Matricarin was detected in fractions 7 and 8, but the latter contained it only in traces. Matricarin, as a chamomile ingredient, was introduced in 1959 by Cekan et al. In later literature we have found data only about the presence in Achillea and Artemisia species [43, 44]. In bioautographic in vitro experiments matricarin (in fraction 7) slightly affected Psmlux as well as Bs (Fig. 5). Other antibiotic components in compact spots with similar, low $\mathrm{R}_{\mathrm{f}}$ can be detected in more fractions (Figs. 4 and 5). Their source, according to the blank development (Fig. 10), is the original adsorbent bed (bleeding), not the plant extract.

Fraction 9, including low amount of fatty acids, and fraction 10 without any identified component, had no antibacterial effect against Gram-positive Bs, while the Gram-negative Psmlux was slightly susceptible to fraction 9 (Fig. 6). However, because fatty acids display antibacterial activity usually against Gram-positive bacteria and to a much lesser extent against the Gram-negatives [45], it can be assumed that not the antibacterial effect of fatty acids was observed, they might have been in too low a concentration in the adsorbent layer.

Coumarins herniarin and umbelliferone were detected in fractions 4 and 11. We have to note that herniarin appeared first in the fourth peak (fraction), but it was there in all further fractions in a quite low concentration because of peak tailing. These chamomile fractions and the umbelliferone test substance, at the same $\mathrm{R}_{\mathrm{f}}$ with the main component of fraction 11, showed growth inhibiting effect in the case of Psmlux (Figs. 4 and 6). Bs was modestly sensitive to the presence of herniarin (Fig. 4), but not to umbelliferone (not showed). These results may prove that chamomile coumarins can play a role in the plant defence against not only fungal but also bacterial attack.

\section{CONCLUSIONS}

On-line OPLC can be exploited for the efficient separation and isolation of different substances, like antimicrobial components of a complex biological matrix. As usually a TLC method can easily be adapted for OPLC, so it is obvious to use OPLC for isolation of compounds found previously active in a TLC-bioautographic study. Combining this solution with a GC-MS analysis, the results here showed that the antibacterial effect of $50 \%$ ethanolic extract of chamomile is ascribable to cis-, trans-spiroethers, and the coumarins like herniarin and umbelliferone.

\section{ACKNOWLEDGEMENT}

The authors are grateful to József Farkas (Central Food Research Institute, Budapest, Hungary) for Bacillus subtilis, and to Jun Fan (John Innes Centre, Department of Disease and Stress Biology, Norwich, UK) for providing luminescent Pseudomonas syringae pv. maculicola.

This work was partially supported by OTKA grant No. PD83487.

\section{REFERENCES}

[1] Bisset, N.G.; Wichtl, M. Herbal Drugs and Phytopharmaceuticals: A Handbook for Practice on a Scientific Basis, $2^{\text {nd }}$ ed.; CRC Press: Boca Raton, FL, 2001.

[2] World Health Organization. Monographs on Selected Medicinal Plants, vol. 1: Flos Chamomillae. WHO, Geneva, 1999. pp. 86.

[3] Srivastava, J.K.; Gupta, S. In: Complementary and Alternative Therapies in the Aging Population; Watson, R.R., Ed.; Elsevier Inc., Academic Press. 2009; pp. 135-158.

[4] McKay, D.L.; Blumberg, J.B. A review of the bioactivity and potential health benefits of chamomile tea (Matricaria recutita L.). Phytother. Res., 2006, 20, 519-530.

[5] Szőke, É.; Máday, E.; Kiss, S.A.; Sonnewend, L.; Lemberkovics, E. Effect of magnesium on essential oil formation of genetically transformed and nontransformed chamomile cultures. J. Am. Coll. Nutr., 2004, 23, 763S-767S.

[6] Repcák, M.; Imrich, J.; Franeková, M. Umbelliferone, a stress metabolite of Chamomilla recutita (L.) Rauschert. J. Plant Physiol., 2001,158, 1085-1087.

[7] Gilbertson, G.; Koenig, T.R. Essential oils and related products. Anal. Chem., 1981, 53, 61-77.

[8] Szőke, É.; Máday, E.; Tyihák, E.; Kuzovkina, I.N.; Lemberkovics, É. New terpenoids in cultivated and wild chamomile (in vivo and in vitro). J. Chromatogr. B, 2004, 800, 231-238.

[9] Lis-Balchin, M.; Deans, S.G.; Eaglesham, E. Relationship between bioactivity and chemical composition of commercial essential oils. Flavour Fragr. J., 1998, 13, 98 -104.

[10] Aggag, M.E.; Yousef, R.T. Study of antimicrobial activity of chamomile oil. Planta Med., 1972, 22, 140-144.

[11] Berry, M. The chamomiles. Pharm. J., 1995, 254, 191-193.

[12] Soliman, K.M.; Badeaa, R.I. Effect of oil extracted from some medicinal plants on different mycotoxigenic fungi. Food Chem. Toxicol., 2002, 40, $1669-1675$. 
Separation and identification of antibacterial chamomile components

[13] Al-Ismail, K.M.; Talal, A. A study of the effect of water and alcohol extracts of some plants as antioxidants and antimicrobial on long-term storage of anhydrous butter fat. Dirasat. Agric. Sci., 2003, 30, 330-337.

[14] Cinco, M.; Banfi, E.; Tubaro, A.; Loggia, R.D. A microbiological survey on the activity of a hydroalcoholic extract of chamomile. Int. J. Drug. Res., 1983, 21, 145-151.

[15] Shikov, A.N.; Pozharitskaya, O.N.; Makarov, V.G.; Kvetnaya, A.S. Antibacterial Activity of Chamomilla recutita Oil Extract against Helicobacter pylori. Phytother. Res., 2008, 22, 252-253.

[16] Daniel, M.; Purkayastha, R.P. Handbook of Phytoalexin Metabolism and Action. Dekker Inc: New York, 1995.

[17] Ojala, T.; Remes, S.; Haansuu, P.; Vuorela, H.; Hiltunen, R.; Haahtela, K.; Vuorela, P.; Antimicrobial activity of some coumarin containing herbal plants growing in Finland. J. Ethnopharmacol., 2000, 73, 299-305.

[18] Afek, U.; Orenstein, J.; Carmeli, S.; Rodov, V.; Bar, J.M. Phytochemistry., 1999, 50, 1129-1132.

[19] Jurd, L.; King Jr., A.D.; Mihara, K.; Antimicrobial properties of umbelliferone derivatives. Phytochemistry., 1971, 10, 2965-2970.

[20] Eliašová, A.; Repcák, M.; Pastírová, A.; Quantitative changes of secondary metabolites of Matricaria chamomilla by abiotic stress. Z. Naturforsch. C, 2004, 59c, 543-548.

[21] Wagner, H.; Bladt, S. Plant Drug Analysis, 2nd ed.; Springer-Verlag: Berlin Hejdelberg New York, 2001.

[22] Botz, L.; Nagy, S.; Kocsis, B.; In: Planar Chromatography - A Retrospective View for the Third Millennium; Nyiredy, Sz. Ed.; Springer: Budapest, 2001. pp. 489-516.

[23] Weins, C.; Jork, H.; Toxicological evaluation of harmful substances by in situ enzymatic and biological detection in high-performance thin-layer chromatography. J. Chromatogr. A, 1996, 750, 403-407.

[24] Móricz, Á.M.; Tyihák, E.; Ott, P.G. Usefulness of transgenic luminescent bacteria in direct bioautographic investigation of chamomile extracts. J. Planar Chromatogr., 2010, 23, 180-183.

[25] Móricz, Á.M.; Horváth, Gy.; Molnár, P.; Kocsis, B.; Böszörményi, A.; Lemberkovics, É.; Ott, P.G. Investigation of thyme (Thymus vulgaris L.) essential oil in BioArena system. J. Planar Chromatogr., 2010, 23, 406-410.

[26] Choma, I.M.; The use of thin-layer chromatography with direct bioautography for antimicrobial analysis. LC-GC Europe, 2005, 11, 482-288.

[27] Mincsovics, E.; Garami, M.; Kecskés, L.; Tapa, B.; Végh, Z.; Kátay, Gy.; Tyihák, E. Personal Overpressured-Layer Chromatography (OPLC) Basic System Flexible Tool in Analytical and Semipreparative Work. J. AOAC Int., 1999, 82, 587-598.

[28] Mincsovics, E.; Kátay, Gy.; Ott, P.G.; Király-Véghely, Zs.; Móricz, Á.M.; Tyihák, E. Isolation of some antimicrobial compounds of red wine by OPLC flowing eluent wall technique. Chromatographia, 2005, 62, S51-S56 Suppl. S

[29] P.Z. Wang, R.H. Doi, Overlapping promoters transcribed by Bacillus subtilis $\sigma^{55}$ and $\sigma^{37}$ RNA polymerase holoenzymes during growth and stationary phase. J. Biol. Chem., 1984, 259, 8619-8625.

[30] Fan, J.; Crooks, C.; Lamb, C. High-throughput quantitative luminescence assay of the growth in planta of Pseudomonas syringae chromosomally tagged with Photorhabdus luminescens luxCDABE. Plant J., 2008, 53, 393-399.

[31] Anagnostopoulos, C.; Spizizen, J. Requirements for transformation in Bacillus subtilis. J. Bacteriol., 1961, 81, 741-746.

[32] King, E.O.; Ward, M.K.; Raney, D.E. Two simple media for the demonstration of pyocyanin and fluorescin. J. Lab. Clin. Med., 1954, 44, 301-307.

[33] Iordache, A.; Culea, M.; Gherman, C.; Cozar, O. Characterization of some plant extracts by GC-MS. Nucl. Instrum. Methods Phys. Res. B, 2009, 267, 338-342.

[34] Adams, R.P. Identification of essential oil components by gas chromatography/quadrupole mass spectroscopy. Allured Publ. Corp.: Carol Stream, USA, 2001.

[35] Szőke, É.; Máday, E.; Gershenzon, J.; Allen, J.L.; Lemberkovics, É. $\beta$-Eudesmol, a New Sesquiterpene Component in Intact and Organized Root of Chamomile (Chamomilla recutita). J. Chromatogr. Sci., 2004, 42, 229-233.

[36] Van den Dool, H., Kratz, P.D. A generalization of the retention index system including linear temperature programmed gas-liquid partition chromatography. J. Chromatogr., 1963, 11, 463-471.

[37] Cekan, Z.; Prochazka, V.; Herout, V.; Sorm, F. Isoln from Matricaria chamomilla L. and Artemisia tilesii Ledeb, Compositae. Collect. Czech. Chem. Commun., 1959, 24, 1554-1557. 
Separation and identification of antibacterial chamomile components

[38] Máday, E.; Szentmihályi, K.; Then, M.; Szőke, É. Mineral element content of chamomile. Acta Alim., 2000, 29, 51-57.

[39] Christensen, L.P. In: Bioactive Foods in Promoting Health: Fruits and Vegetables; Watson, R.; Preedy, V.R. (Eds.); Elsevier, 2010, pp. 285-306.

[40] Cavalieri, E.; Mariotto, S.; Fabrizi, C.; Carcereri de Prati, A.; Gottardo, R.; Leone, S.; Berra, L.V.; Lauro, G. M.; Ciampa, A. R.; Suzuki, H. a-Bisabolol, a nontoxic natural compound, strongly induces apoptosis in glioma cells. Biochem. Biophysi. Res. Commun., 2004, 315, 589-594.

[41] Baghalian, K.; Haghiry, A.; Naghavi, M.R.; Mohammadi, A. Effect of saline irrigation water on agronomical and phytochemical characters of chamomile (Matricaria recutita L.). Sci. Hortic., 2008, 116, 437-441.

[42] Smelcerovic, A.; Lamshoeft, M.; Radulovic, N.; Ilic, D.; Palic, R. LC-MS Analysis of the Essential Oils of Achillea millefolium and Achillea crithmifolia. Chromatographia, 2010, 71, 113-116.

[43] Todorova, M.; Trendafilova, A.; Mikhova, B.; Vitkova, A.; Duddeck, H. Chemotypes in Achillea collina based on sesquiterpene lactone profile. Phytochemistry, 2007, 68, 1722-1730.

[44] Suleimenov, E.M.; Smagulova, F.M.; Morozova, O.V.; Raldugin, V.A.; Bagryanskaya, I.Yu.; Gatilov, Yu.V.; Yamovoi, V.I.; Adekenov, S.M. Sesquiterpene lactones and flavonoids from Artemisia albida. Chem. Nat. Comp., 2005, 41, 689-691.

[45] Kabara, J.J.; Swieczkowski, D.M.; Conley A.J.; Truant, J.P. Fatty acids and derivatives as antimicrobial agents. Antimicrob. Agents. Chemother., 1972, 2, 23-28.
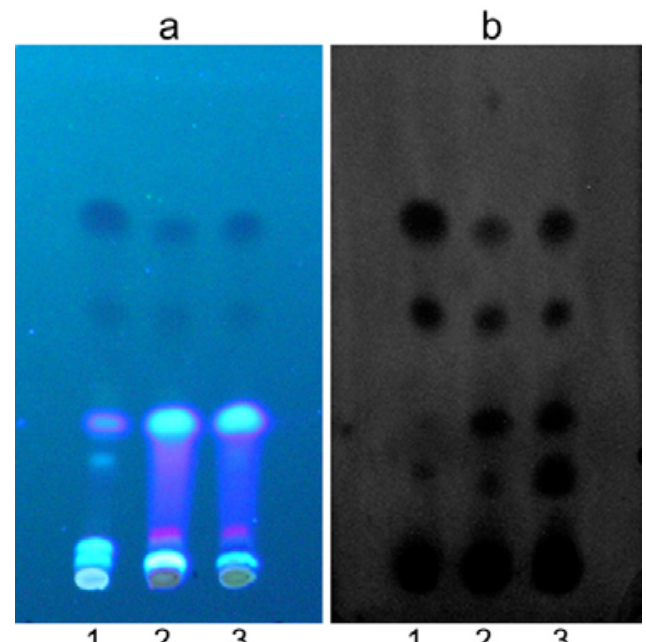

Fig. (1). Antibacterial effect of 50\% aqueous ethanol extracts of chamomile roots (1), leaves (2) and flowers (3) against Pseudomonas savastanoi pv. maculicola; Each extract $(10 \mu \mathrm{L})$ was applied and developed with chloroformacetone 99:1 (v/v) as the mobile phase;

a - the developed plate seen under UV light (365 nm) before biological detection;

$\mathrm{b}$ - the bioautogram obtained by use of luminescent Psmlux bacteria. Their emitted light was collected with a cooled camera (dark areas mean inhibition zones). 
Separation and identification of antibacterial chamomile components

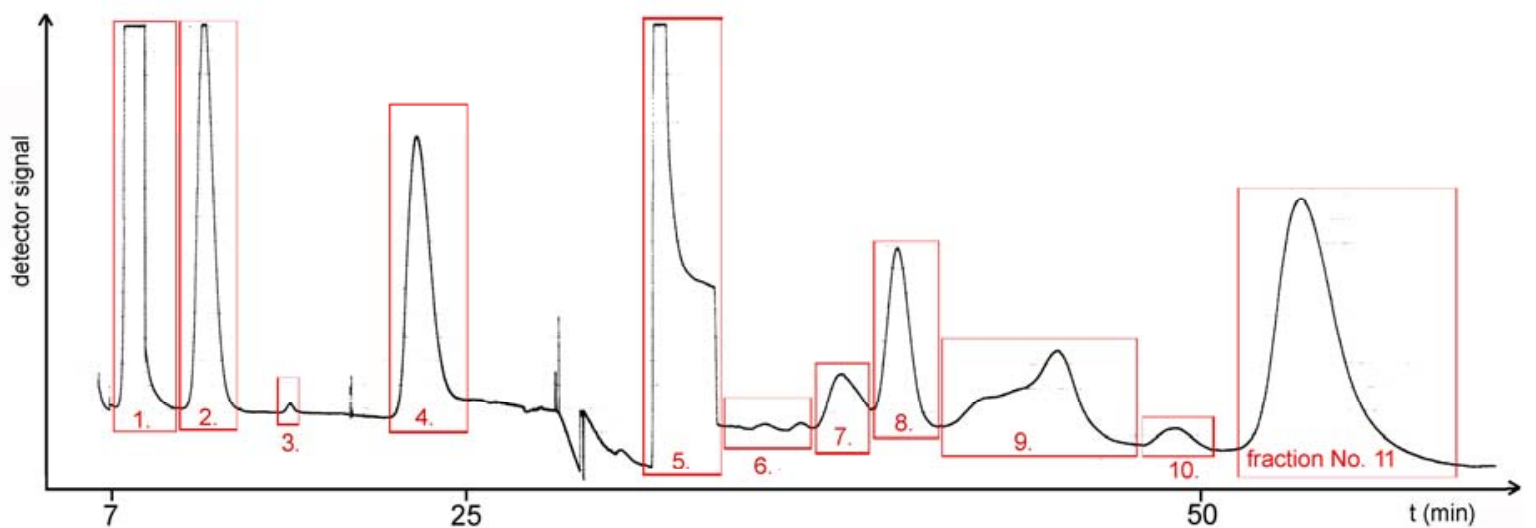

Fig. (2). OPLC separation of $0.5 \mathrm{~mL}$ chamomile extract and the 11 collected fractions; OPLC conditions were as follows: 50 bar external pressure, $450 \mu \mathrm{L}$ rapid mobile-phase flush, $1 \mathrm{~mL} \mathrm{~min}{ }^{-1}$ mobile phase flow rate; The mobilephase was: 0-30 min 100\% chloroform (first step), from 30 min chloroform-acetone 95:5 (v/v) (second step) and the UV detection was achieved at 350 and $320 \mathrm{~nm}$, respectively.
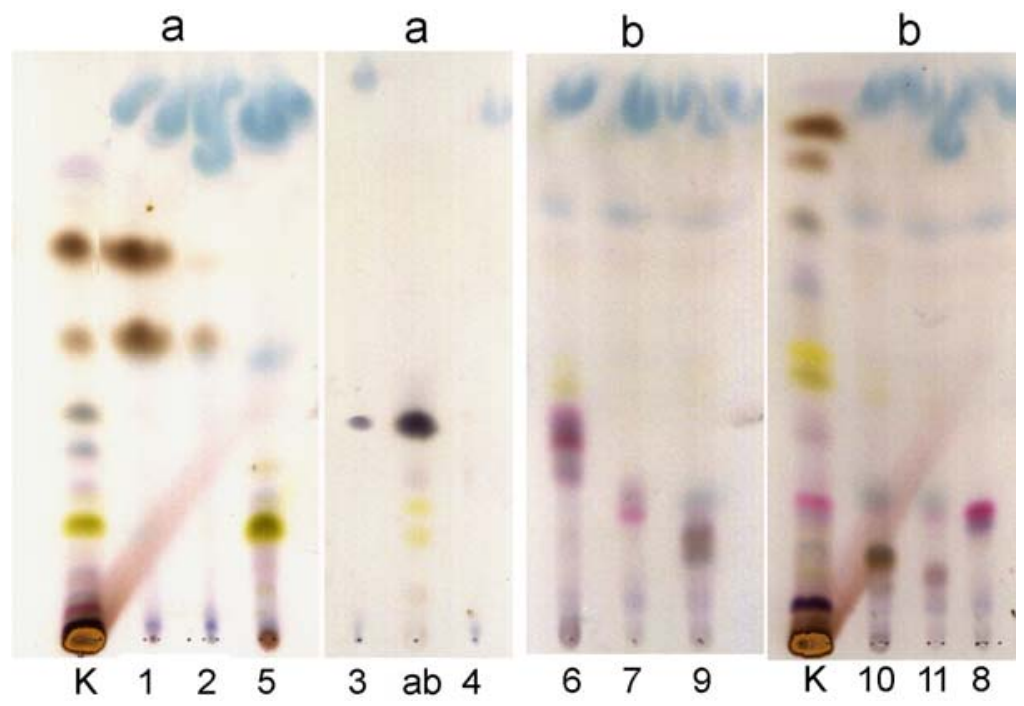

Fig. (3). TLC study of chamomile extract and the collected fractions visualized by vanillin-sulphuric reagent; $\mathrm{K}-10 \mu \mathrm{L}$ of chamomile extract, 1-11- the fractions, ab- $5 \mu \mathrm{g}$ of alpha-bisabolol;

a - layers were developed with chloroform-acetone 99:1 (v/v);

b - layers were developed with chloroform-acetone 95:5 (v/v). 
Separation and identification of antibacterial chamomile components

a

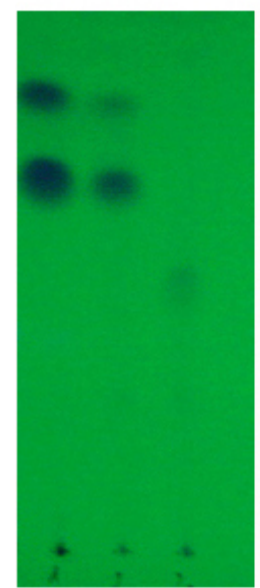

123 a

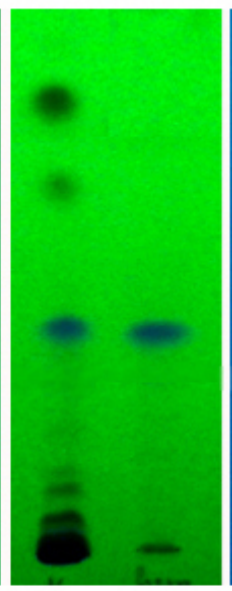

K 4 b

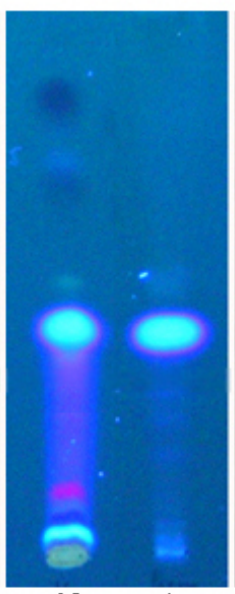

K
C

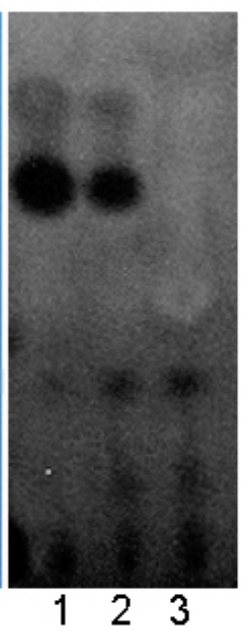

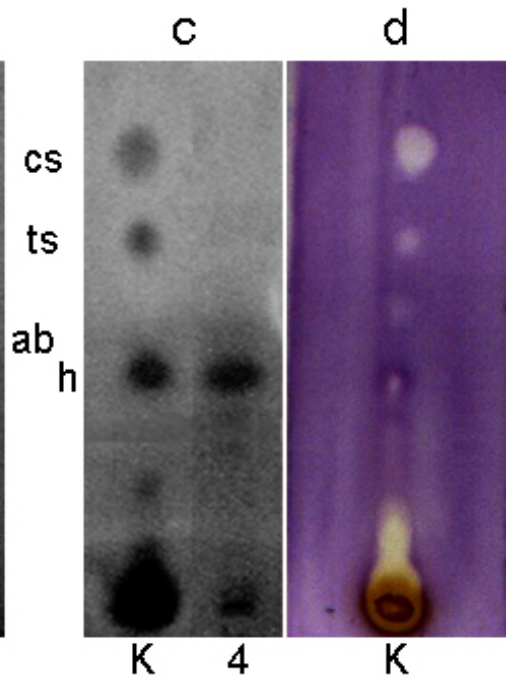

Fig. (4). Bioautographic detection of chamomile extract (K, $10 \mu \mathrm{L})$ and the collected fractions (1-4) against Pseudomonas savastanoi pv. maculicola and Bacillus subtilis;

$\mathrm{a} / \mathrm{b}$ - the developed layers under UV light $254 / 365 \mathrm{~nm}$;

c- bioautogram using luminescent $P$. maculicola (dark spot $=$ inhibition zone);

d- bioautogram using B. subtilis (light spot = inhibition zone);

The layers were developed with chloroform-acetone 99:1 (v/v) as mobile phase; cs - cis-spiroether, ts - trans-spiroether, ab - alpha-bisabolol, $\mathrm{h}$ - herniarin.
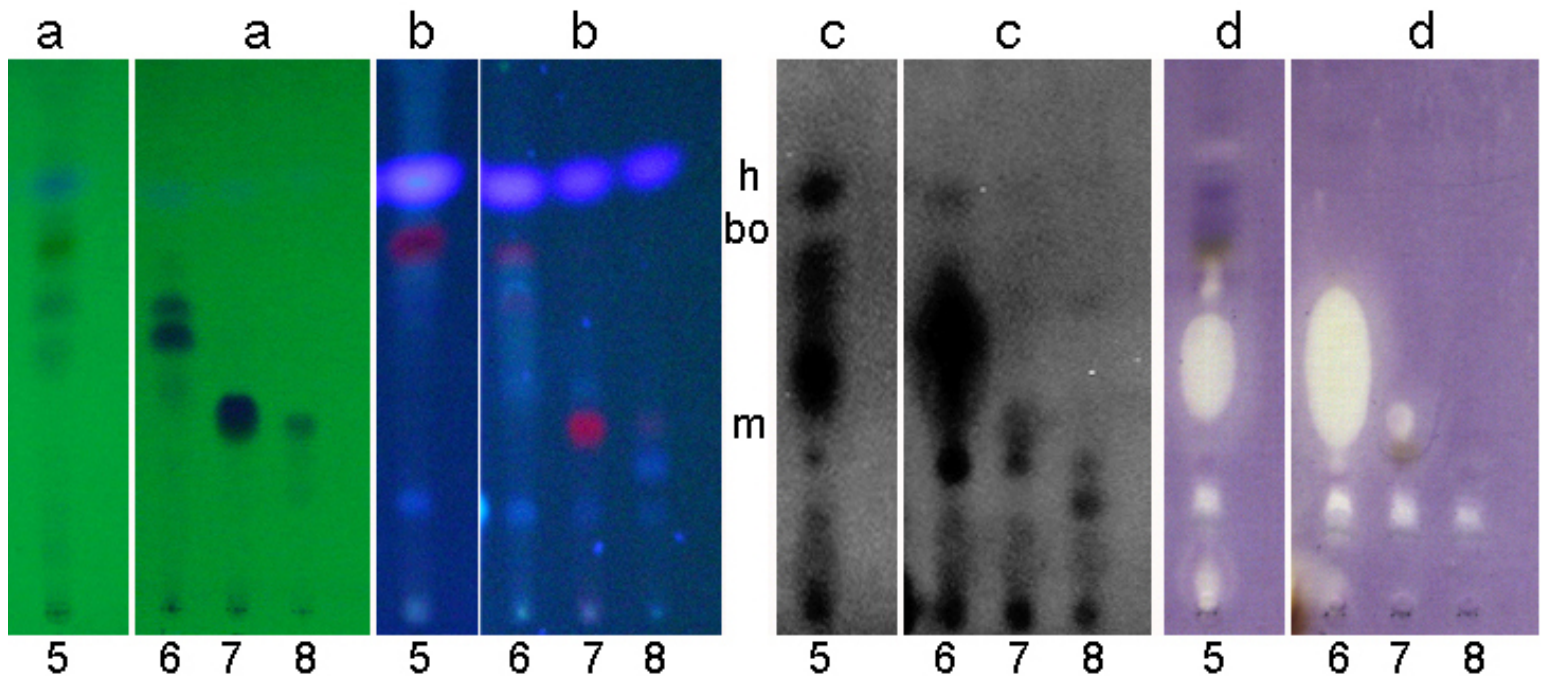

Fig. (5). Bioautographic detection of the collected fractions (5-8) against Pseudomonas savastanoi pv. maculicola and Bacillus subtilis;

$\mathrm{a} / \mathrm{b}$ - the developed layers under UV light $254 / 365 \mathrm{~nm}$;

c- bioautogram using luminescent $P$. maculicola (dark spot $=$ inhibition zone);

d- bioautogram using B. subtilis (light spot = inhibition zone);

The layers were developed with chloroform-acetone 95:5 (v/v) as mobile phase;

$\mathrm{h}$ - herniarin, bo - bisabolol oxides, $\mathrm{m}$ - matricarin. 
Separation and identification of antibacterial chamomile components

a

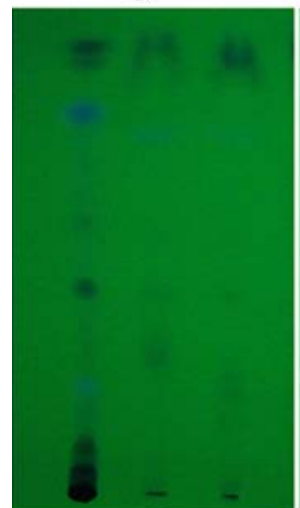

$\begin{array}{lll}\mathrm{K} & 9 & 10\end{array}$ a

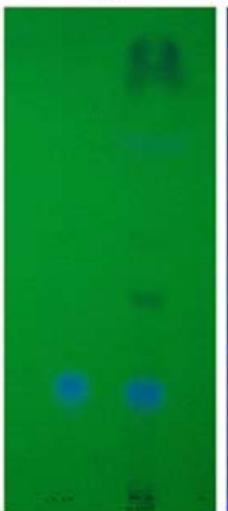

u 11 b

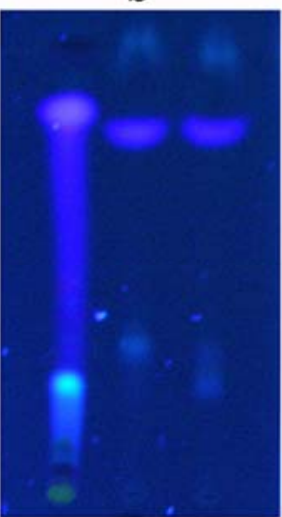

$\begin{array}{lll}\mathrm{K} & 9 & 10\end{array}$ b

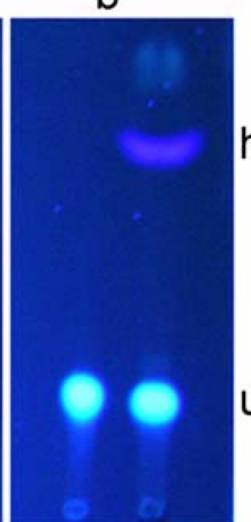

U 11

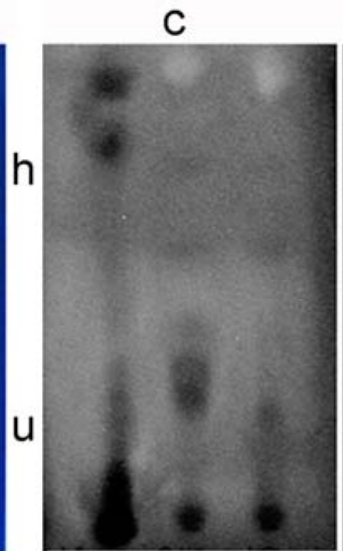

K 910
C

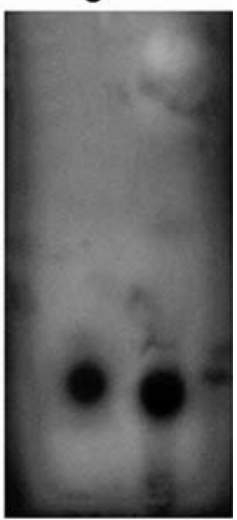

u 11

Fig. (6). Bioautographic detection of chamomile extract $(\mathrm{K}, 10 \mu \mathrm{L})$, the collected fractions (9-11) and umbelliferone $(\mathrm{u}, 3 \mu \mathrm{g})$ against Pseudomonas savastanoi pv. maculicola;

$\mathrm{a} / \mathrm{b}$ - the developed layers under UV light $254 / 365 \mathrm{~nm}$;

c- bioautogram using luminescent $P$. maculicola (dark spot $=$ inhibition zone);

The layers were developed with chloroform-acetone 95:5 (v/v) as mobile phase;

$\mathrm{h}$ - herniarin, $\mathrm{u}$ - umbelliferone. 
Separation and identification of antibacterial chamomile components

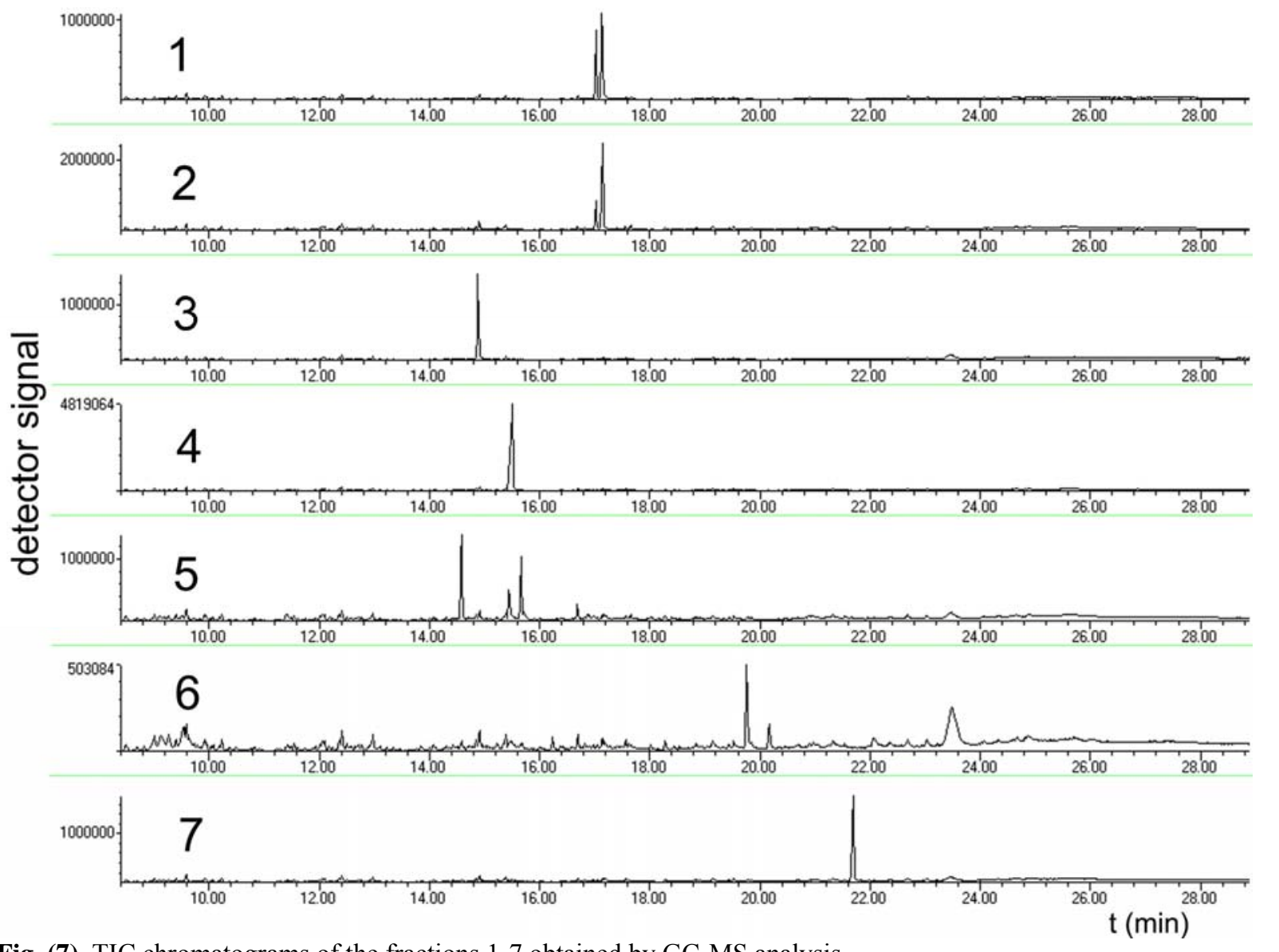

Fig. (7). TIC chromatograms of the fractions 1-7 obtained by GC-MS analysis.
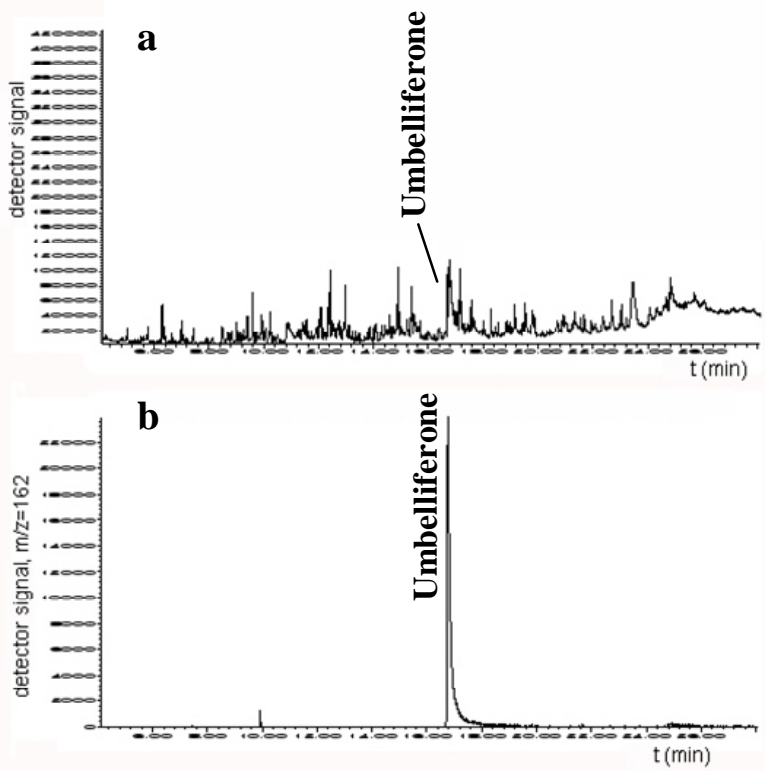

Fig. (8). GC-MS analysis of the fraction 11: (a) TIC chromatogram; (b) extracted ion chromatogram (162 amu; the molecular ion of umbelliferone). 
Separation and identification of antibacterial chamomile components
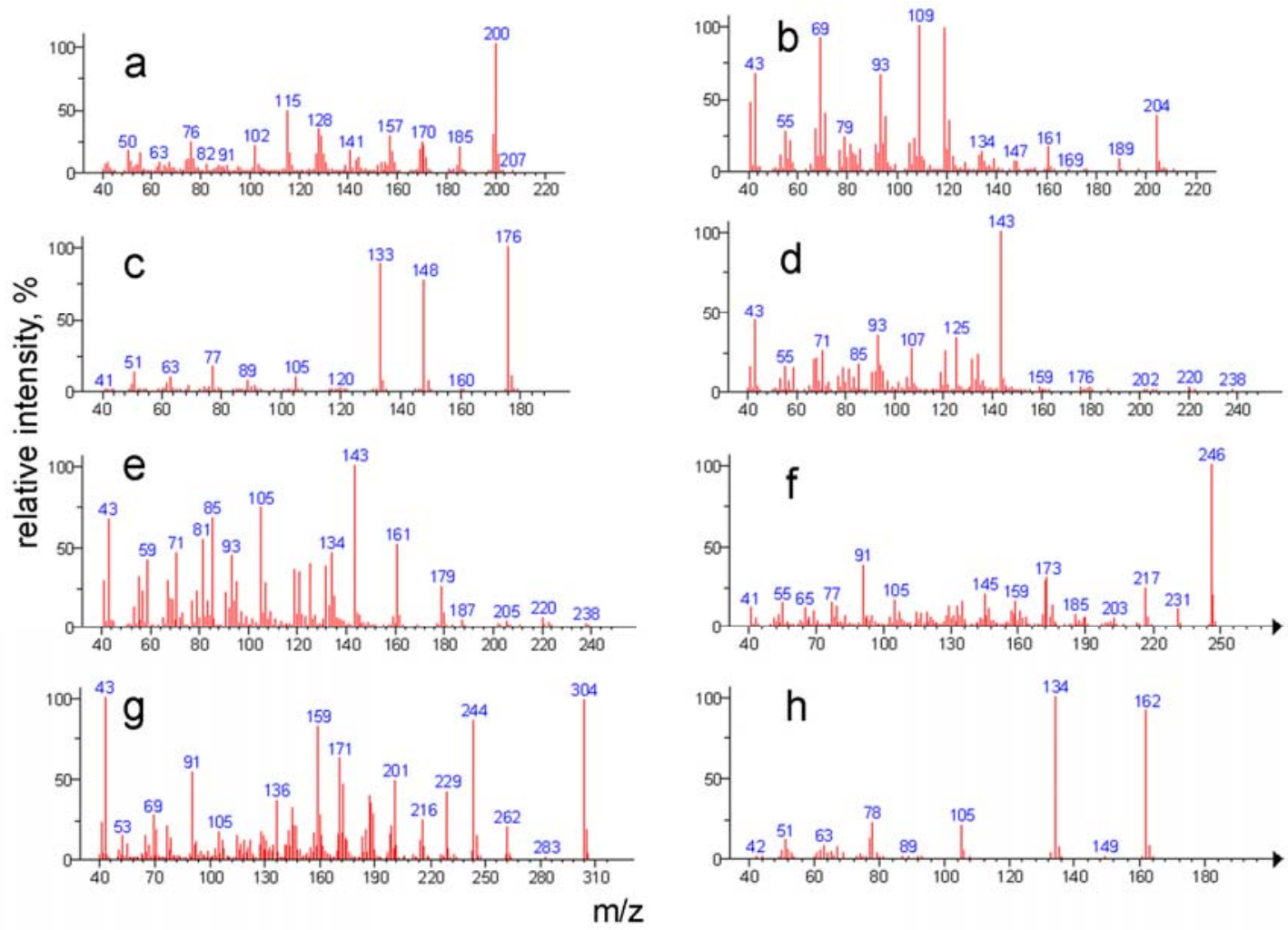

Fig. (9). The MS spectra of the main components of the chamomile fractions;

$\mathrm{a}$ - peaks in fraction 1 and 2 at $\mathrm{t}_{\mathrm{R}} 17.02$ and $17.13 \mathrm{~min}$, identified as cis- and trans-spiroethers;

$\mathrm{b}$ - peak in fraction 3 at $t_{R} 14.89 \mathrm{~min}$, identified as alpha-bisabolol;

$\mathrm{c}$ - peak in fraction 4 at $t_{\mathrm{R}} 15.46 \mathrm{~min}$, identified as herniarin;

$\mathrm{d}$ - peak in fraction 5 at $\mathrm{t}_{\mathrm{R}} 15.65 \mathrm{~min}$, identified as bisabolol oxide $\mathrm{A}$;

$\mathrm{e}$ - peak in fraction 5 at $\mathrm{t}_{\mathrm{R}} 14.57 \mathrm{~min}$, identified as bisabolol oxide $\mathrm{B}$;

$\mathrm{f}$ - peak in fraction 6 at $t_{R} 19.74$ min, identified as achillin;

$\mathrm{g}$ - peak in fraction 7 at $t_{\mathrm{R}} 21.67$ min, identified as matricarin;

$\mathrm{h}$ - peak in fraction 11 at $\mathrm{t}_{\mathrm{R}} 16.80 \mathrm{~min}$, identified as umbelliferone. 
Separation and identification of antibacterial chamomile components

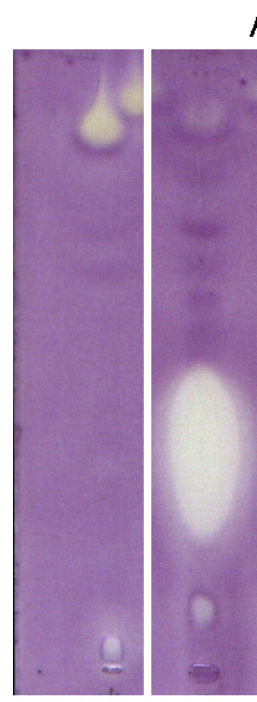

b1
A

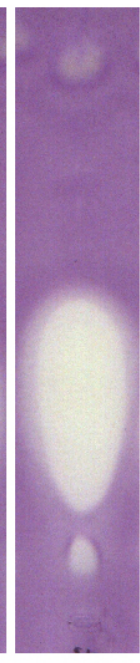

b3

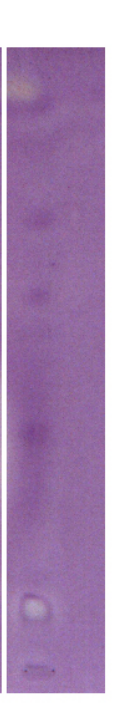

b4

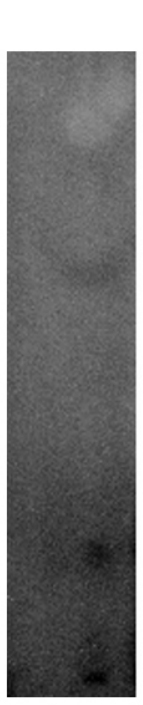

b1

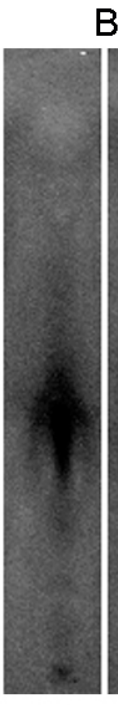

b2

B

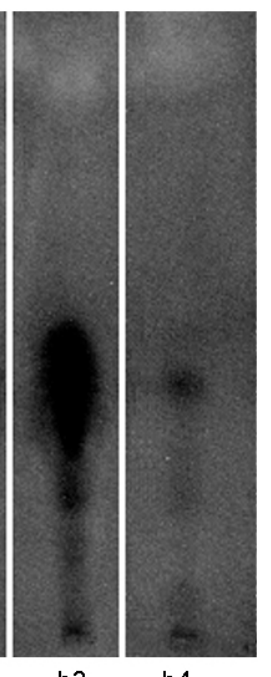

b4

Fig. (10). Bioautographic detection of fractions collected during the blank development;

b1: 7.30-15 $\min$ (in $1^{\text {st }}$ gradient step), b2: 37.30-40 min (parallel with chamomile fraction 5), b3: 40-45 min (similar as that of chamomile peak 6), and b4: 45-55 min;

A - bioautogram using B. subtilis (light spot = inhibition zone);

$\mathrm{B}$ - bioautogram using luminescent $P$. maculicola (dark spot $=$ inhibition zone);

Fraction b1 was developed with chloroform-acetone 99:1 (v/v) as mobile phase, b2-b4 were chromatographied with chloroform-acetone 95:5 (v/v). 
Separation and identification of antibacterial chamomile components

Table 1. The chamomile components, identified by GC-MS

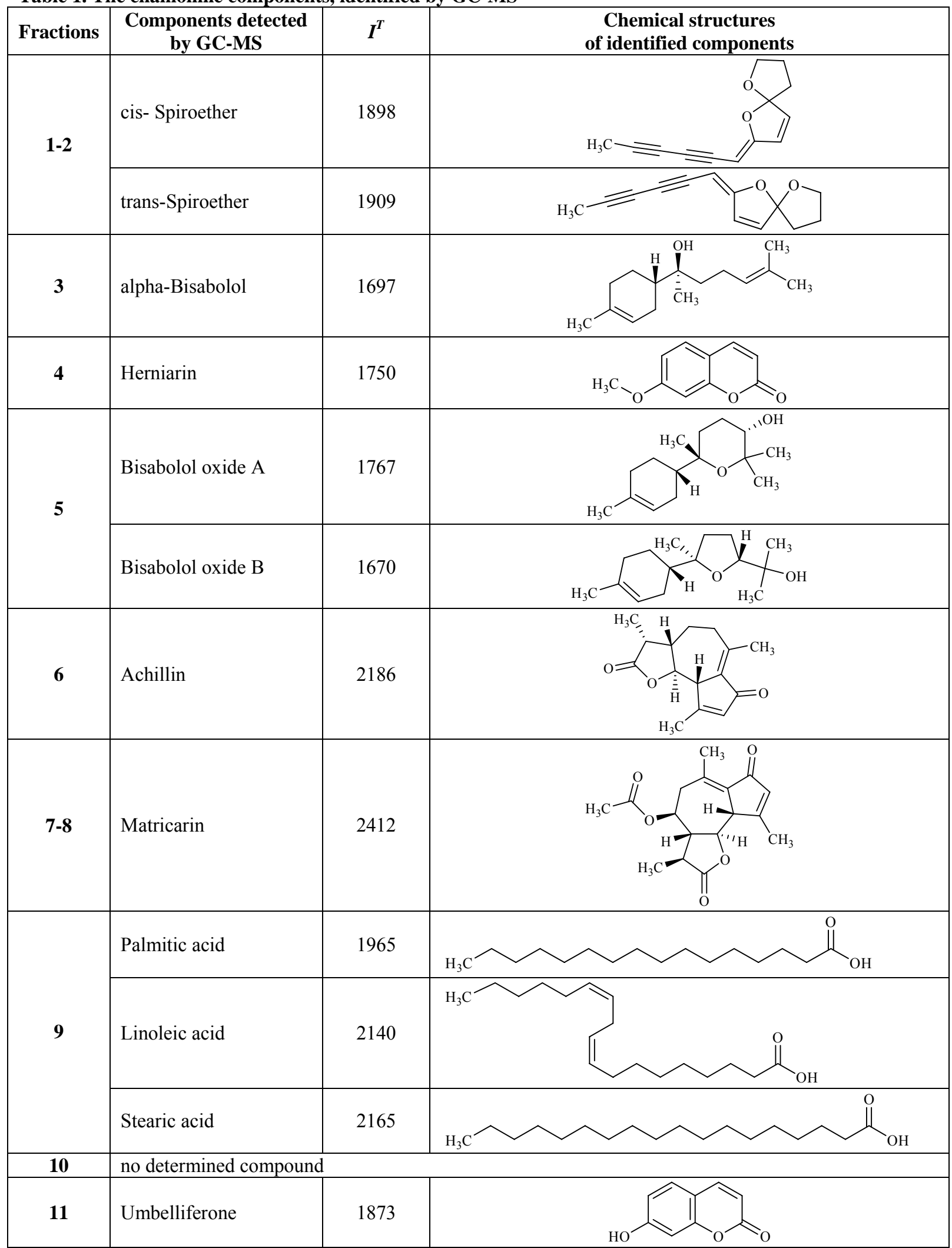

$I^{T}$ : temperature programmed retention index 